\title{
Evaluation of bile duct stones extracted by ERCP (Endoscopic Retrograde Cholangio-Pancreatography).
}

\footnotetext{
1. MBBS, FCPS (Medicine) FCPS (Gastroenterology) Associate Professor Gastroenterology Nishtar Hospital Multan. 2. MBBS

Ex-Resident Gastroenterology Nishtar Hospital Multan.
}

Correspondence Address: Dr. Waseem Sarwar Malghani Department of Gastroenterology Nishtar Hospital Multan. malghanidr@gmail.com

Article received on: 26/01/2021

Accepted for publication: $15 / 04 / 2021$

\begin{abstract}
Waseem Sarwar Malghani ${ }^{1}$, Azmat Ullah Nasir ${ }^{2}$
ABSTRACT... Objective: To determine the frequency of different types of gallstones on ERCP stone extraction from bile duct. Study Design: Cross Sectional study. Setting: Department of Gastroenterology of the Nishtar Hospital Multan. Period: September 2019 to October 2020. Material \& Methods: Patients with bile duct stones on imaging of either sex aged $18-70$ years were included in our study while patients with IHD, malignancies, liver cirrhosis, asthma, TB, COPD, ILD and pregnant women were excluded from our study. During ERCP the gross appearance of extracted stones and related findings were noted. Results: Our study included 139 patients meeting inclusion criteria, of these 139 study cases, 49 (35.3\%) were male and 90 $(64.7 \%)$ were female patients with bile duct stone. Mean age was $45.78 \pm 12.05$ year (range; $27-68$ years). Of these 139 study cases, $56(40.3 \%)$ were from rural areas, $83(59.7 \%)$ were from urban areas, $52(37.4 \%)$ had poor socioeconomic status and $87(62.6 \%)$ were from middle income family background. Diabetes was noted in 35 (25.2\%), hypertension in $53(38.1 \%)$ and obesity in $32(23 \%)$ (Mean BMl was $\left.26.53 \pm 214 \mathrm{~kg} / \mathrm{m}^{2}\right)$. Mean stone size in our study was 15.82 $\pm 6.34 \mathrm{~mm}$ while $78(56.12 \%)$ had single stones. Pure cholesterol gallstones were noted in $47(33.8 \%)$, mixed cholesterol stones in $71(51.1 \%)$ and brown pigmented gall stones in 21 (15.1\%). Conclusion: Mixed cholesterol stones were more frequent followed by pure cholesterol and brown pigmented stones in bile duct gallstones patients. Mixed cholesterol stones were significantly associated with rural residential status and hypertension while brown pigmented stones were residential status, hypertension and obesity.
\end{abstract}

Key words: $\quad$ Bile Duct, Gallstones, Mixed Cholesterol.

Article Citation: Malghani WS, Nasir Azmat Ullah. Evaluation of bile duct stones extracted by ERCP (Endoscopic Retrograde Cholangio-Pancreatography). Professional Med J 2021; 28(12):1732-1736.

https://doi.org/10.29309/TPMJ/2021.28.12.6286

\section{INTRODUCTION}

Bile duct stone disease (choledocholithiasis) is a common problem in daily clinical practice. ${ }^{1}$ Understanding completely the types of bile duct stones, and the pathophysiological changes underlying the formation of each type of stone remains a challenge for current and future optimal management. 2,3 Based on chemical composition and gross appearance, gallstones are divided into three types. The majority of gallstones are cholesterol stones which consist mainly of cholesterol monohydrate crystals and precipitates of amorphous calcium bilirubinate often with calcium carbonate or phosphate. ${ }^{4}$ These stones are usually subclassified as either pure cholesterol or mixed stones that contain at least $50 \%$ cholesterol by weight. Pure cholesterol crystals are typically yellow in color and nodular. ${ }^{5}$ Mixed stones are grey white to black, tend to be smaller and faceted. Established risk factors for cholesterol stones include female gender, obesity, dyslipidemia, diabetes. Remaining gallstones are pigment stones that contain mostly calcium bilirubinate and are subclassified into 2 groups black pigment stones and brown pigment stones. ${ }^{6}$ Rare gallstones $(\sim 0.5 \%)$ include calcium carbonate stones and fatty acid calcium stones. Gallstones are also classified by their location as intrahepatic, bile duct stones (choledocholithiasis) ${ }^{7,8}$ Intrahepatic stones are predominantly brown pigment stones. Gallbladder stones are mainly cholesterol stones with a minority being black pigment stones. $^{9}$ Bile duct stones are composed mainly of mixed 
cholesterol stones. ${ }^{10}$

Clinical presentations associated with bile duct stone include biliary pain, obstructive jaundice, cholangitis, and biliary pancreatic. Imaging modalities used for diagnosis include transabdominal ultrasound and MRCP. ERCP has been considered the standard treatment for removal of bile duct stones. ${ }^{11}$ Stones in the bile duct may be secondary that come from gallbladder or primary that form denovo within the bile duct. Secondary stones are usually of cholesterol type. Black pigment stone which are associated with chronic hemolysis also form in the gallbladder but rarely enter the bile duct. Most pigment stones in the bile duct are primary and are associated with bile stasis, periampullary diverticulae and recurrent biliary tract infections. ${ }^{12}$

This study was conducted to document different types of gallstones on ERCP to help clinicians to ascertain current magnitude of underlying etiological factors of choledocholithiasis in our population which will help them to anticipate such underlying causes for better management of these patients.

\section{MATERIAL \& METHODS}

This Cross Sectional study was conducted in the Department of Gastroenterology of the Nishtar Hospital Multan from 01-09-2019 to 30-10-2020 using non-probability consecutive sampling technique. A total 139 patients undergoing gallstone extraction from bile duct on ERCP were included. Sample size was calculated using 10\% frequency of pure cholesterol ${ }^{13}$ employing WHO sample size calculator at $95 \% \mathrm{Cl}$ and $5 \%$ margin of error. Patients with bile duct stones on imaging of either sex aged 18-70 years were included in our study while patients with IHD, malignancies, liver cirrhosis, asthma, TB, COPD, ILD and pregnant women were excluded from our study. Basic demographics were noted and informed consent was taken from ensuring confidentiality and fact that no risk involved to patient while taking part in the study. During ERCP the gross appearance of extracted stones and related findings were noted. Pure cholesterol gallstones were defined by their gross appearance, being yellow in color with nodular or smooth surface. Mixed cholesterol gallstones were defined by their gross appearance as grey white to black, mostly smaller and faceted. Brown pigment gallstones; based on gross appearance.

Data was analyzed with statistical analysis program (SPSS version 20). Frequency and percentage was computed for qualitative variables like gender, diabetes, obesity, age groups and types of bile duct stones. Mean SD was presented for quantitative variables like age. Effect modifiers like age, gender, residential status and diabetes were controlled by stratification. Post stratification chi Square test was applied to see their effect on outcome. P value of less than 0.05 was considered statistically significant. This study was approved by ethical committee (23483/NMU \& H).

\section{RESULTS}

Our study included 139 patients meeting inclusion criteria, of these 139 study cases, 49 (35.3\%) were male and 90 (64.7\%) were female patients with bile duct stone. Mean age was 45.78 \pm 12.05 year (range; 27-68 years). Of these 139 study cases, 56 (40.3\%) were from rural areas, 83 $(59.7 \%)$ were from urban areas, $52(37.4 \%)$ had poor socioeconomic status and $87(62.6 \%)$ were from middle income family background. Diabetes was noted in 35 (25.2\%), hypertension in 53 (38.1\%) and obesity in 32 (23\%) (Mean BMI was $\left.26.53 \pm 214 \mathrm{~kg} / \mathrm{m}^{2}\right)$. Mean stone size in our study was $15.82 \pm 6.34 \mathrm{~mm}$ while 78 (56.12\%) had single stones. Pure cholesterol gallstones were noted in 47 (33.8\%), mixed cholesterol stones in $71(51.1 \%)$ and brown pigmented gall stones in $21(15.1 \%)$.

\section{DISCUSSION}

Gallstones in the bile duct are the major indication endoscopic retrograde cholangiopancreatography (ERCP) and have significant impact on quality of life and productivity of the patients. ${ }^{14,15}$ There has been significant improvements in management strategies in recent decades with rapid advancement and evolution of research in biliary system. ${ }^{14}$ 


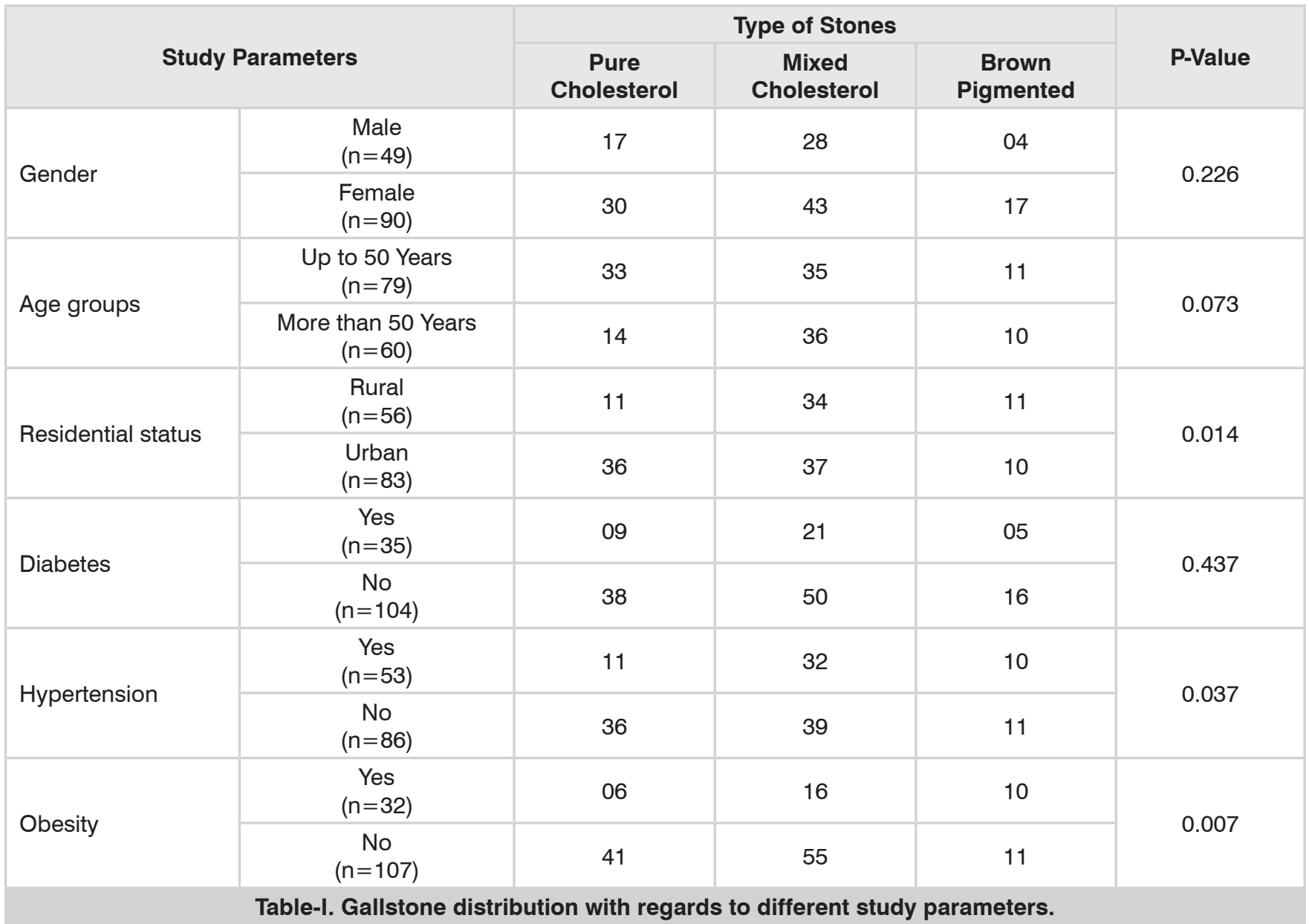

Our study included 139 patients meeting inclusion criteria, of these 139 study cases, 49 (35.3\%) were male and $90(64.7 \%)$ were female patients with bile duct stone. Odemis et $\mathrm{al}^{16}$ has also reported $62 \%$ female patients with bile duct gall stones, similar to our results. Elghamry et al ${ }^{17}$ from Egypt has also reported $70 \%$ female gender preponderance. Sattar et al ${ }^{18}$ from Karachi has also reported $73 \%$ patients with bile duct stones were females, similar to our results. Lauri et al $^{19}$ from UK has also reported 55\% female patients with bile duct gallstones. However Khawar et $\mathrm{al}^{20}$ from Karachi has reported different results showing male gender predominance in bile duct gall stone patients.

Mean age was $45.78 \pm 12.05$ year (range; 27 68 years). Odemis et $\mathrm{al}^{16}$ has reported $63.3 \pm$ 17 years mean age, which is slightly higher than our results. Elghamry et al ${ }^{17}$ from Egypt has also reported $48.90 \pm 11.84$ years mean age of bile duct stone patients, close to our results. Sattar et $\mathrm{al}^{18}$ from Karachi has also reported 48 years mean age of bile duct stone patients, close to our results. Lauri et al $^{19}$ from UK has reported 69 years mean age of these patients.

Of these 139 study cases, 56 (40.3\%) were from rural areas, 83 (59.7\%) were from urban areas, $52(37.4 \%)$ had poor socioeconomic status and $87(62.6 \%)$ were from middle income family background. Diabetes was noted in 35 (25.2\%), hypertension in $53(38.1 \%)$ and obesity in 32 (23\%) (Mean BMI was $26.53 \pm 214 \mathrm{~kg} / \mathrm{m}^{2}$ ). Elghamry et $\mathrm{al}^{17}$ from Egypt has also reported $10 \%$ controlled diabetes and $30 \%$ controlled hypertension which is in compliance with our results. Sattar et $\mathrm{al}^{18}$ from Karachi has also reported similar results.

In our study 78 (56.12\%) had single stones. Elghamry et al $^{17}$ from Egypt has also reported $60 \%$ single stones, similar to our results. 
Odemis et $\mathrm{al}^{16}$ has reported similar results. Pure cholesterol gallstones were noted in 47 (33.8\%), mixed cholesterol stones in $71(51.1 \%)$ and brown pigmented gall stones in 21 (15.1\%). In literature, cholesterol has been reported to be main component which is found in as many as $80 \%$ extracted stones with $10 \%$ of these stones may be pure cholesterol, in our study cholesterol stones were predominantly more frequent. High burden of cholesterol stones in our population points towards early management strategies, as these are associated with high risk of infections.

\section{CONCLUSION}

Mixed cholesterol stones were more frequent followed by pure cholesterol and brown pigmented stones in bile duct gallstones patients. Mixed cholesterol stones were significantly associated with rural residential status and hypertension while brown pigmented stones were residential status, hypertension and obesity. Prevalence of high proportion cholesterol stones emphasizes the need for early management to avoid future complications like infection.

Copyright(C) 15 Apr, 2021.

\section{REFERENCES}

1. Hormati A, Ghadir MR, Sarkeshikian SS, Alemi F, Moghaddam M, Ahmadpour S, Mohammadbeigi A, Sivandzadeh GR. Adding ursodeoxycholic acid to the endoscopic treatment and common bile duct stenting for large and multiple biliary stones: Will it improve the outcomes? BMC Gastroenterol. 2020 Nov 10; 20(1):374. doi: 10.1186/s12876-020-01523-5. PMID: 33172395; PMCID: PMC7653844.

2. Choi JH, Lee TY, Cheon YK. Effect of stent placement on stone recurrence and post-procedural cholangitis after endoscopic removal of common bile duct stones. Korean J Intern Med. 2020 Aug 24. doi: 10.3904/ kjim.2020.060. Epub ahead of print. PMID: 32829571.

3. Park $\mathrm{CH}$. The Management of Common Bile Duct Stones. Korean J Gastroenterol. 2018 May 25; $71(5): 260-263$. Korean. doi: 10.4166/kjg.2018.71.5.260. PMID: 29791984.
4. Lyu Y, Cheng Y, Li T, Cheng B, Jin X. Laparoscopic common bile duct exploration plus cholecystectomy versus endoscopic retrograde cholangiopancreatography plus laparoscopic cholecystectomy for cholecystocholedocholithiasis: A meta-analysis. Surg Endosc. 2019 Oct; 33(10):32753286. doi: 10.1007/s00464-018-06613-w. Epub 2018 Dec 3. PMID: 30511313.

5. Bourgouin $S$, Truchet $X$, Lamblin $G$, De Roulhac J, Platel JP, Balandraud P. Dynamic analysis of commonly used biochemical parameters to predict common bile duct stones in patients undergoing laparoscopic cholecystectomy. Surg Endosc. 2017 Nov; 31(11):4725-4734. doi: 10.1007/s00464-017-55492. Epub 2017 Apr 13. PMID: 28409371.

6. Li MK, Tang CN, Lai EC. Managing concomitant gallbladder stones and common bile duct stones in the laparoscopic era: A systematic review. Asian J Endosc Surg. 2011 May; 4(2):53-8. doi: 10.1111/j.17585910.2011.00073.x. Epub 2011 Mar 17. PMID: 22776221.

7. Hosseini SV, Ayoub A, Rezaianzadeh A, Bananzadeh AM, Ghahramani L, Rahimikazerooni S, Khazraei H. A survey on concomitant common bile duct stone and symptomatic gallstone and clinical values in Shiraz, Southern Iran. Adv Biomed Res. 2016 Aug 30; 5:147. doi: 10.4103/2277-9175.187402. PMID: 27656616; PMCID: PMC5025909.

8. Chen $\mathrm{H}$, Jorissen $\mathrm{R}$, Walcott J, Nikfarjam M. Incidence and predictors of common bile duct stones in patients with acute cholecystitis: A systematic literature review and meta-analysis. ANZ J Surg. 2020 Sep; 90(9):1598-1603. doi: 10.1111/ans.15565. Epub 2019 Nov 19. PMID: 31743951.

9. Kenny R, Richardson J, McGlone ER, Reddy M, Khan OA. Laparoscopic common bile duct exploration versus pre or post-operative ERCP for common bile duct stones in patients undergoing cholecystectomy: Is there any difference? Int J Surg. 2014; 12(9):989-93. doi: 10.1016/j.ijsu.2014.06.013. Epub 2014 Jul 4. PMID: 24998206.

10. Singh AN, Kilambi R. Single-stage laparoscopic common bile duct exploration and cholecystectomy versus two-stage endoscopic stone extraction followed by laparoscopic cholecystectomy for patients with gallbladder stones with common bile duct stones: Systematic review and meta-analysis of randomized trials with trial sequential analysis. Surg Endosc. 2018 Sep; 32(9):3763-3776. doi: 10.1007/s00464-018-6170-8. Epub 2018 Mar 30. PMID: 29603004. 
11. Vettoretto N, Arezzo A, Famiglietti F, Cirocchi R, Moja $\mathrm{L}$, Morino M. Laparoscopic-endoscopic rendezvous versus preoperative endoscopic sphincterotomy in people undergoing laparoscopic cholecystectomy for stones in the gallbladder and bile duct. Cochrane Database Syst Rev. 2018 Apr 11; 4(4):CD010507. doi: 10.1002/14651858.CD010507.pub2. PMID: 29641848; PMCID: PMC6494553.

12. Tan C, Ocampo O, Ong R, Tan KS. Comparison of one stage laparoscopic cholecystectomy combined with intra-operative endoscopic sphincterotomy versus two-stage pre-operative endoscopic sphincterotomy followed by laparoscopic cholecystectomy for the management of pre-operatively diagnosed patients with common bile duct stones: a meta-analysis. Surg Endosc. 2018 Feb; 32(2):770-778. doi: 10.1007/s00464017-5739-y. Epub 2017 Jul 21. PMID: 28733744.

13. Bortoff GA, Chen MY, Ott DJ, Wolfman NT, Routh WD. Gallbladder stones: imaging and intervention. Radiographics. 2000 May-Jun; 20(3):751-66. doi: 10.1148/radiographics.20.3.g00ma16751. PMID: 10835126.

14. Ojo AS, Pollard A. Risk of gallstone formation in aberrant extrahepatic biliary tract anatomy: A Review of Literature. Cureus. 2020 Aug 25; 12(8):e10009. doi: 10.7759/cureus.10009. PMID: 32864277; PMCID: PMC7449616.
15. Kwon OS, Kim YK, Her KH, Kim HJ, Lee SD. Physical activity can reduce the prevalence of gallstone disease among males: An observational study. Medicine (Baltimore). 2020 Jun 26; 99(26):e20763. doi: 10.1097/MD.0000000000020763. PMID: 32590752; PMCID: PMC7329018.

16. Ödemiş B, Kuzu UB, Öztaş E, Saygılı F, Suna N, Coskun $O$, et al. Endoscopic management of the difficult bile duct stones: A single tertiary center experience. Gastroenterol Res Pract. 2016; 2016:8749583. doi: 10.1155/2016/8749583. Epub 2016 Nov 24. PMID: $27999591 ;$ PMCID: PMC5143714.

17. Elghamry EE, Elsheikh MM, Mohamed HA. Evaluation of different methods of laparoscopic treatment of common bile duct stones. Int Surg J. 2019; 6(8):267076.

18. Sattar I, Aziz A, Rasul S, Mehmood Z, Khan A. Frequency of infection in cholelithiasis. J Coll Physicians Surg Pak. 2007; 17(1):48-50.

19. Lauri A, Horton RC, Davidson BR, Burroughs AK, Dooley JS. Endoscopic extraction of bile duct stones: management related to stone size. Gut. $1993 \mathrm{Dec}$; 34(12):1718-21. doi: 10.1136/gut.34.12.1718. PMID: 8282260; PMCID: PMC1374470.

20. Kalwar HA, Furqan M, Awan RH, Shaikh H, Shaikh SS, Mujtaba G. Prevalence of common bile duct stones on endoscopic retrograde cholangiopancreatography in gallstone pancreatitis with deranged liver function. Med Forum. 2020; 31(1):58-62.

\begin{tabular}{|c|c|c|c|}
\hline \multicolumn{3}{|c|}{ AUTHORSHIP AND CONTRIBUTION DECLARATION } \\
\hline No. & \multicolumn{1}{|c|}{ Author(s) Full Name } & Contribution to the paper & Author(s) Signature \\
\hline 1 & Waseem Sarwar Malghani & 1st Author & \\
\hline 2 & Azmat Ullah Nasir & 2nd Author & \\
\hline
\end{tabular}

